\title{
“SERÁ UM GRANDE DE APRENDIZADO": UMA ANÁLISE DESCRITIVA DOS ASPECTOS LINGUÍSTICOS DA ESCRITA DE SURDOS EM PBL2 - INTERFACES ENTRE TEXTUALIDADE, USO E COGNIÇÃO NO ESTADO DE INTERLÍNGUA
}

"IT WILL BE A GREAT LEARNING": A DESCRIPTIVE ANALYSIS OF THE LINGUISTIC ASPECTS OF THE WRITTEN LANGUAGE OF DEAF IN PBL2 - INTERFACES BETWEEN TEXTUALITY, USE AND COGNITION IN THE INTERLANGUAGE STAGE

\author{
Roberto Freitas $\mathrm{Jr}^{1}$, Lia Abrantes Antunes Soares ${ }^{1}$, Hosana Sheila da Rosa Xavier \\ Freitas ${ }^{1}$, João Paulo da Silva Nascimento ${ }^{1}$ \\ Universidade Federal do Rio de Janeiro (UFRJ), Rio de Janeiro, RJ, Brasil \\ robertofrei@hotmail.com; lia.soares@gmail.com; rosa.hosana59@gmail.com; jpn0401@gmail.com
}

Recebido em: 14 mar.2018

Aceito em: 23 abr.2018

Resumo: A pesquisa consiste em um modelo investigativo diferenciado sobre o texto escrito de surdos universitários, pelo qual busca-se a descrição de problemas de gramaticalidade e de desvios de norma culta. Além da descrição, permeada pela análise do impacto desses problemas no nível da textualidade, busca-se identificar os processos cognitivos, típicos da Interlíngua, subjacentes ao surgimento dos fenômenos. Os textos selecionados foram do gênero discursivo e-mail e os resultados revelaram problemas de diferentes naturezas presentes na produção escrita desses indivíduos.

Palavras-chave: Interlíngua. Escrita. Surdez.

Abstract: The research consists of a differentiated investigative model on the written text of undergraduate deaf people, by which the description of problems of grammaticality and deviations of standard language issought. In addition to the description, permeated by the analysis of the impact of these problems on the textual level, we seek to identify Interlanguage cognitive processes underlying the phenomena. The e-mail was the selected genre and results revealed different nature problems present in the written production of these individuals.

Keywords: Interlanguage. Writing. Deafness.

\section{Introdução}

A situação educacional do Brasil, a despeito de avanços recentes, provocados pelo desenvolvimento de tecnologias e investimentos educacionais, ainda se configura precária, se comparada aos números internacionais. Questões como o analfabetismo funcional e o analfabetismo digital denunciam tal situação e deve provocar, entre demais aspectos, pesquisas que visem, em última instância, apresentar possíveis caminhos para o desenvolvimento da educação nesse país.

Nesse sentido, o presente artigo visa apresentar os primeiros resultados de uma pesquisa, ainda em andamento, sobre a escrita do surdo universitário. Assim como tantos outros estudantes brasileiros, o aluno universitário surdo, ao deparar-se com a 
realidade e demandas do ensino superior, pode encontrar uma dificuldade específica, a saber, o domínio da língua escrita, em suas possibilidades gramaticais e discursivotextuais.

Sem dúvida, o domínio da língua escrita, em particular o da denominada norma culta, é desafio para qualquer indivíduo, em qualquer nível de escolaridade em que se encontre. O problema, entretanto, torna-se acentuado, quando o aluno ingressante no nível superior não apresenta tal domínio, o que pode gerar grande comprometimento de seu desenvolvimento acadêmico e profissional.

Não é nenhuma novidade que a realidade do texto escrito do surdo adulto pode apresentar, ainda, problemas de maior grau de especificidades características desse público, muitas vezes gerados pela inadequação de políticas públicas e de metodologias de ensino de escrita para um público que requer particular atenção no que concerne esse tipo de aprendizado.

É nesse sentido que a presente pesquisa se caracteriza. Investigamos, aqui, o texto escrito do surdo universitário, buscando mapear problemas de produção escrita, para fins de contribuição a futuras pesquisas sobre ensino de língua escrita para surdos. Entretanto, diferentemente de muitos trabalhos nessa área, buscamos aqui, ainda, identificar possíveis problemas que são específicos do texto do surdo e que, portanto, requerem metodologias diferenciadas e adaptadas para fins de superação desses desafios.

Entendemos que investigar o texto escrito do aluno surdo universitário significa, em última análise, contribuir para o pensar da práxis educacional nos diferentes níveis de ensino. Ao mapearmos, minimamente, os aspectos que podem comprometer a produção textual do aluno universitário, além de criarmos a oportunidade necessária para a melhoria do ensino desse aluno, estamos abrindo um espaço de discussão acerca do ensino desses aspectos nos níveis mais elementares do ensino para surdos.

Certamente, o tratamento das questões supracitadas pode representar uma realidade dolorida que parte dos problemas educacionais gerais do país e que desembocam, neste caso, nas especificidades de ensino de língua escrita para surdos. A tradição de ensino de línguas orais para surdos, em suas modalidades escritas, prevê seu tratamento segundo o rótulo de L2. Obviamente, tal 
posicionamento consiste em um movimento político salutar em prol da educação do surdo, posto que busca considerar a realidade desse aluno para fins de maior adequação de seu ensino. Por outro lado, esse mesmo posicionamento pode se configurar em um grande problema, se pensarmos em questionamentos inseridos em dois grandes eixos, a saber, expectativas sobre níveis de proficiência escrita e definição de aspectos que caracterizam a escrita desse público-alvo, determinantes para direcionamento das práticas de ensino.

Em primeiro lugar,o que se espera em termos de aprendizado desta L2, ou seja, que nível de proficiência escrita em L2 devemos esperar de um estudante universitário e que tem, nessa mesma L2, o principal veículo de divulgação de conhecimentos em seu próprio país?

Em segundo lugar, qual é realmente nosso conhecimento acerca do texto escrito do surdo, suas potencialidades, limitações e características diversas? Será que nos pautamos em generalizações superficiais, muitas vezes, inclusive, pautadas em pesquisas acerca da produção textual do ouvinte nativo? Essas considerações superficiais consistem em exercícios eficazes em busca da adequação e consequente melhoria do ensino para surdos? Assumir simplesmente que determinados aspectos do texto do surdo o definem como um texto de segunda língua garante sua inclusão, ou mesmo, permitem a melhoria de seu ensino em prol do desenvolvimento de seu letramento?

As questões acima levantadas trazem à tona toda a história de lutas pela inclusão de surdos e, por isso, são de difícil enfrentamento. Também é fato que os avanços e conquistas em termos de educação de surdos são inquestionáveis. É preciso nesse momento, porém, pensarmos, talvez, de modo ainda mais direcionado, sobre as questões relacionadas ao seu letramento, especialmente, em tempos de reformulação do próprio conceito de letramento, se pensarmos em termos de inclusão digital e de suas possibilidades de inclusão para os surdos.

Optamos, assim, por desenvolver um estudo que circule na investigação de três áreas importantes e definidoras da qualidade de qualquer texto escrito: a) questões ligadas à (a)gramaticalidade, b) questões ligadas à adequação às normas, culta e/ou padrão, mais típicas do texto escrito e c) questões ligadas à textualidade e os fatores que podem comprometer a coesão e a coerência textual, em maior ou menor grau. 
Por se tratar de uma investigação linguística strictu senso a pesquisa visa, portanto, a investigação de aspectos linguísticos, em termos descritivos, da produção escrita do surdo, buscando entender, ainda, sua relação com aspectos cognitivos atuantes no processo de produção de textos na língua alvo, como a hipercorreção, a supergeneralização, e outros possíveis processos cognitivos que se configuram na caracterização da interlíngua.

\section{Pressupostos Teóricos}

O avanço das pesquisas em aquisição de segunda língua (SLA) ainda não possibilitou a explicação da questão em sua amplitude. Freitas (2011) discute a contribuição de teorias de SLA, que buscam, diferentemente, o entendimento do desenvolvimento da interlíngua, a partir do papel exercido por universais linguísticos e comunicativos e dos ambientes de aprendizagem/aquisição. E é neste sentido que desenvolvemos o presente trabalho: segundo uma visão teórica ampla sobre o processo de aquisição de L2, em particular, centrado no uso.

Todas essas variáveis apontam para a própria conceituação da interlíngua, visto que aprendizes de diferentes idades e graus de instrução traçam trajetórias desenvolvimentais semelhantes do sistema da L2, apresentando sempre uma variabilidade aparentemente caótica, embora governada por algum sistema subjacente de regras (c.f.: Long, 1994), ou, preferimos dizer, processos cognitivos que definem a emergência de um sistema, uma gramática de L2.

Este sistema, em alguma medida, dependendo dos fatores atuantes em sua formação, apresentará características da L1 do aprendiz e da língua-alvo (LA), além de estruturas nem sempre aceitáveis em nenhum dos dois sistemas, fenômeno comum no contexto de aquisição de uma segunda língua.

Nesse sentido, a interlíngua seria um recorte adaptado de um sistema linguístico, o qual é, potencialmente falando, um modelo a ser adquirido/aprendido. Seria ela construída em diferentes fases e com características fonético-fonológicas, lexicais, morfossintáticas e discursivas, que muitas vezes são distorções e agramaticalidades na $\mathrm{L} 2$, podendo comprometer a inteligibilidade do processo comunicativo (Freitas, 2011).

A literatura de SLA apresenta dois termos que se destacam como fenômenos recorrentes na aquisição de uma L2: a transferência e a generalização. Embora sejam 
processos distintos, eles se aproximam no sentido de serem manifestações de um mesmo princípio: o do encontro de material já adquirido com o material em processo de aquisição.

Para Brown (1994), a transferência é um termo geral que abarca o uso de conhecimentos prévios no aprendizado da L2. Quando o conhecimento auxilia o aprendizado, temos transferência positiva, mas quando o deturpa, é considerada negativa e é traduzida, principalmente pela abordagem behaviorista, como interferência. No passado, muitos entendiam o alcance de alto nível de proficiência como a superação de efeitos 'negativos' transpostos da L1.

Neste cenário, emerge a Análise Contrastiva (AC), segundo a qual uma abordagem científica e estruturalista das duas línguas em questão permitiria apontar diferenças e contrastes e assim prever o que poderia ser objeto de dificuldade para o aprendiz (cf. Brown, 1994,193). Da mesma forma, seriam previsíveis ambientes que não favoreceriam a interferência e não dificultariam a aquisição. Logo, a influência da língua materna representaria a influência de hábitos anteriores do aprendiz, alguns potencialmente úteis e outros potencialmente perigosos para o processo de aquisição da L2.

O fenômeno da generalização aponta para o papel do indivíduo como ator importante em seu próprio processo de aprendizagem. A partir de regras e conhecimentos já adquiridos, o aprendiz de uma L2 poderá apresentar dados novos no uso da LA, sem comprometimento de sentidos por não serem erros. A partir dos anos 70, segundo Odlin $(1989,17)$, a análise contrastiva passa a ser questionada, principalmente devido à evolução dos estudos empíricos sobre transferência e análise de erros.

Dentre as causas para seu questionamento apontamos: a) as diferenças entre línguas que nem sempre representam importante dificuldade de aprendizado; b) a ocorrência de erros que não parecem ser explicados por influência da L1, mas por universais linguísticos empíricos; c) a ocorrência de erros que não parecem ser explicados por influência da L1, mas por influência do método de ensino - erros induzidos (cf. Stenson, 1974) - e d) a ocorrência de erros espontâneos supergeneralizaões (overgeneralizations). Assim, apesar de a Hipótese da Análise Contrastiva $(\mathrm{CAH})$ apresentar evidências de influência da $L 1$, a comparação da $L 1$ 
com a LA só seria útil se feita para explicar a previsibilidade de ocorrência de certos tipos de erros, e ainda assim, segundo Odlin (1989), sem dados reais dos erros dos aprendizes, pouco pode ser realmente considerado previsível. Se a generalização diz respeito a nossa habilidade de, a partir de inferência de regras e leis aprendidas, projetar conhecimentos anteriores em contextos novos em que as regras se adaptam, o termo overgeneralization (supergeneralização de regras) é usado na referência de aplicação de regras em contextos em que elas não são necessárias, ou mesmo permitidas.

A transferência, positiva ou negativa, a generalização e a supergeneralização, em certos estágios da aquisição de $L 2$, podem, ou não, ser processos considerados específicos dessas fases, embora não exclusivas do processo de aquisição de L2, já que estudos em diferentes línguas mostram a generalização e a supergeneralização, por exemplo, acontecendo com aprendizes de diferentes $L 1$, tanto na produção da $L 1$ quanto da L2. Além do mais, muitos linguistas defendem que, se na aquisição da língua materna o indivíduo apresenta diferentes estágios desenvolvimentais, este mesmo fato poderia sugerir a influência de outros fatores no processo de SLA, tais como a atuação de universais de aquisição, os quais seriam também responsáveis por estágios desenvolvimentais da L2.

$\mathrm{Na}$ obra Language, usage, and cognition (2010), Bybee trata dos processos cognitivos de domínio geral que subjazem a formação das línguas, mostrando como palavras se juntam para formar construções. A noção de construção é muito cara a este contexto teórico, posto ser a construção, um pareamento mínimo de forma e sentido, a unidade básica da língua, organizada em uma rede de construções, a gramática. Assim, as construções são representações cognitivas a partir das quais emergem os dados reais da língua em uso.

A autora mostra como processos cognitivos moldam a gramática da língua na memória, dando conta de diferentes possibilidades de usos e gerando mudanças linguísticas ao longo do tempo. Nessa perspectiva, uma teoria da linguagem deveria focalizar os processos dinâmicos que criam as línguas e que fazem delas sistemas adaptativos complexos, na medida em que a língua é vista como um produto emergente da aplicação desses processos (Hopper, 1987; Larsen-Freeman, 1997; Ellis; Larsen-Freeman, 2006). A partir dessa concepção, a autora analisa como os 
processos cognitivos de domínio geral podem derivar os fenômenos estruturais observados na gramática das línguas.

O trabalho de Bybee apresenta, assim, uma visão de linguagem centrada no uso e explica de uma maneira inatista, porém não gerativista, a caracterização da cognição da linguagem, além do próprio processo de sua aquisição. A aquisição de uma L1, aqui, não é vista como algo de tempo pré-definido e dependente de apenas um reduzido, porém suficiente, número de informações linguísticas. Pelo contrário, a aquisição é vista como um processo inacabado, na medida em que um mesmo indivíduo pode adquirir novas construções ao longo da vida, a partir de informações, um tanto redundantes, acerca dessas mesmas construções, se considerarmos o papel da repetição, da frequência de uso de types e tokens(unidades e padrões) em uma dada língua. O que se pretende desenvolver aqui é a ideia de que a repetição de unidades linguísticas, a maior frequência com que elas emergem durante o uso da língua, produz um impacto na representação cognitiva, o que caracteriza a frequência de uso como fator central para a explicação do processo de aquisição.

O ponto que nos interessa aqui diretamente consiste no fato de que esta mesma visão acerca do papel da frequência na aquisição de L1 pode ser estendido a discussões sobre aquisição de L2. No artigo Usage-Based Grammar and Second Language Acquisition (2008), Bybee discute o efeito da frequência para a aquisição e mostra que os mesmos processos cognitivos de domínio geral atuam no curso da aquisição de uma L2, associados ao efeito da frequência de emergência de determinadas unidades e padrões, tendo-se em conta, ainda, o papel da L1.

Nesse sentido, embora não trabalhe com o conceito de interlíngua, a autora mostra que questões relacionadas a transferências e supergeneralizações podem estar associadas ao impacto gerado pela frequência de uso de determinadas construções da L1, ou mesmo da L2, que, ao serem adquiridas, dada a força de sua representação, podem levar a casos de supergeneralizações. Apesar de não utilizarmos diretamente nesta pesquisa os processos cognitivos apresentados por Bybee (2010), propomos uma nomenclatura de processos que supostamente explicam diferentes possibilidades de construções no uso de uma L2, mas que, em última análise, poderiam ser facilmente relacionados aos processos, de ordem ainda mais geral, propostos pela autora. 


\section{Metodologia}

A investigação desenvolvida no presente trabalho, acerca da produção escrita do aluno surdo universitário, reúne os seguintes eixos linguísticos: textualidade, gramaticalidade e adequação às exigências da norma culta em face do contexto escrito em português brasileiro (PB). Inicialmente, mapeamos as instâncias de agramaticalidades e/ou desvios da norma culta detectadas nas produções escritas em PBL2 de alunos surdos universitários do curso de Letras-Libras da Faculdade de Letras - UFRJ, para, então, entrarmos na fase de investigação sobre problemas de textualidade e adequação.

A pesquisa foi realizada com base em sete textos integrantes de um corpus, ainda em processo de criação, o corpus NEIS. Esse corpus é constituído por textos escritos de diferentes gêneros e tipos textuais, produzidos por alunos graduandos do curso de Letras-Libras/UFRJ, surdos e ouvintes, e visa a investigação linguística sobre possíveis problemas de escrita acadêmica desses alunos, em particular, dos surdos. O corpus, que já possui 43 textos apenas de alunos surdos, é parte instrumental do Núcleo de Estudos sobre Interlíngua e Surdez da UFRJ, o NEIS/UFRJ. A Tabela 1 apresenta informações referentes aos textos incorporados ao corpus em 2016:

\begin{tabular}{|c|c|c|c|c|c|c|}
\hline \multicolumn{7}{|c|}{ Corpus NEIS (2016) } \\
\hline \multicolumn{7}{|c|}{ Textos } \\
\hline Informantes & $\begin{array}{l}\text { E-mails } \\
\text { formal/ Informal }\end{array}$ & $\begin{array}{l}\text { Discunso } \\
\text { Diretoj/Indinome }\end{array}$ & Descretivo & Dissertation & Nesrrativo & TOTát \\
\hline 11 & 2 & 2 & 1 & 1 & 1 & 7 \\
\hline 12 & 2 & 2 & 1 & 1 & 0 & 6 \\
\hline 13 & 0 & 0 & 0 & 0 & 0 & 0 \\
\hline 14 & 0 & 2 & 0 & 1 & 1 & 4 \\
\hline 15 & 2 & 0 & 0 & 0 & 2 & 4 \\
\hline 16 & 1 & 2 & $\circ$ & 1 & 2 & 5 \\
\hline 17 & D & a & 1 & 0 & 2 & 3 \\
\hline 18 & 0 & 2 & 1 & 2 & 3 & 8 \\
\hline 19 & 0 & 2. & 1 & 0 & 0 & 3 \\
\hline 110 & D & 2 & 0 & 1 & o & 3 \\
\hline Total & 7 & 14 & 5 & 7 & 11 & 43 \\
\hline
\end{tabular}


Nota-se grifado na Tabela 1 o total de textos da presente pesquisa, 7, na coluna referente ao gênero e-mail. Desse total, quatro eram de registro formal e três de registro informal. A definição de que os gêneros textuais são "entidades sóciodiscursivas e formas de ação social incontornáveis de qualquer situação comunicativa" (Marcuschi, 2005), orientou a escolha do gênero e-mail para investigação, sobretudo por seu caráter produtivo e funcional, concebido na constante interação dialógica da comunidade acadêmica na qual os autores dos textos se encontravam.

A partir da escolha desses textos, o trabalho se desenvolveu da seguinte forma:

a) identificação dos desvios de norma culta e agramaticalidades e posterior agrupamento de dados por categorias de problemas em comum;

b) levantamento dos níveis coesivos em que os problemas se encontravam e o grau de comprometimento da inteligibilidade discursiva (interoracional, intraoracional, interperíodo e interparágrafo);

c) investigação e proposição de processos cognitivos subjacentes a essas ocorrências, que explicariam a emergência de certas construções na Interlíngua (Selinker, 1972 e 1979).

Compreendendo a escrita como uma prática que dispõe de influências de fatores linguísticos e extralinguísticos, durante o processo de constituição do corpus, buscouse considerar o perfil dos autores das produções textuais. Nesse sentido, esgotar o público a um único e categórico perfil, reduzido ao termo surdo, poderia apontar a um indício de pouca produtividade analítica, uma vez que as características textuais podem ser motivadas por fatores de diversos domínios. A comunidade surda também se mostra heterogênea em variados aspectos, assim, houve uma tentativa de controle com relação à uniformidade do perfil dos informantes, considerando a idade, grau de instrução, tipo de surdez (congênita ou adquirida), perfil escolar e tempo de exposição, tanto à LIBRAS, quanto ao português. A Tabela 2 expõe o perfil dos informantes dos textos utilizados nesta pesquisa. 


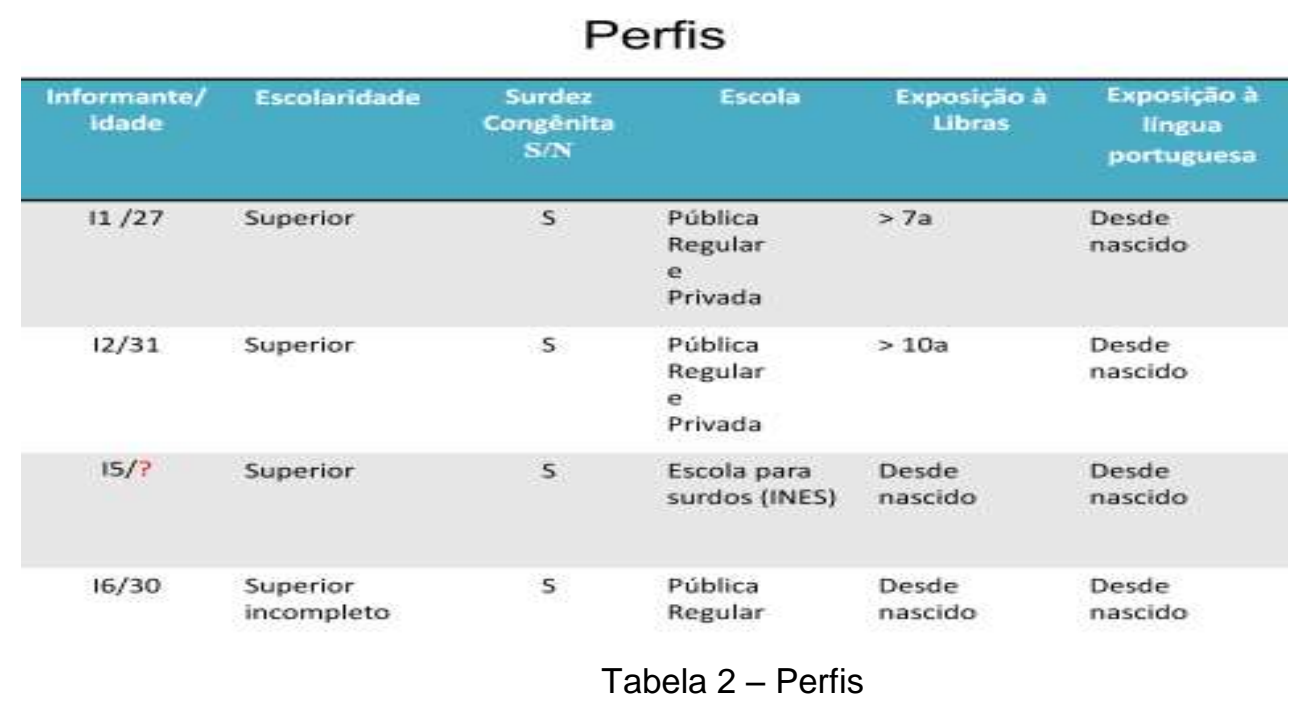

Os sete e-mails selecionados para compor esta pesquisa foram submetidos à análise qualitativa e quantitativa. A primeira se mostrou pertinente para a compreensão dos aspectos linguísticos, quanto ao reconhecimento de padrões que promovem ou não a inteligibilidade comunicativa, ao passo que a segunda amostra mostrou-se favorável ao controle da frequência com a qual as categorias mapeadas surgem e como se instauram no discurso escrito. Entendemos que a investigação da frequência de ocorrência das construções poderia ajudar na compreensão dos fenômenos identificados (Bybee, 2008).

\section{Resultados e Análises}

I. Primeira etapa da pesquisa: identificação e categorização dos problemas de escrita em PBL2 de surdos universitários no gênero e-mail

No percurso da análise linguística dos e-mails selecionados, identificamos diferentes tipos de problema de agramaticalidades e/ou de inadequação à norma culta. A relativa sistematicidade com que alguns problemas ocorriam nos levou a uma proposta de categorização de problemas comuns emergentes no texto escrito do surdo universitário. De maneira geral, essas categorias não só reúnem problemas capazes de comprometer a eficiência da produção escrita em PBL2, mas também evidenciam a necessidade de uma atenção mais específica ao ensino dessa 
modalidade, visto que denotam os pontos de maior dificuldade de indivíduos pertencentes à outra realidade linguística.

As oito categorias mapeadas também em termos de frequência, nas duas variedades de formalidade, além de apontarem aquilo que pode ser esperado da escrita do surdo, configuram alguma contribuição para o trabalho pedagógico a ser realizado por professores de língua portuguesa na modalidade de educação bilíngue, ou inclusiva.

Notamos, dessa forma, que os problemas detectados na escrita dos informantes surdos poderiam ser categorizados da seguinte maneira:

1) Inserção indevida de itens gramaticais;

2) Repetição de itens lexicais/gramaticais;

3) Troca de itens gramaticais/lexicais;

4) Apagamento de itens gramaticais;

5) Problemas de concordância e troca de modo e tempos verbais;

6) Problema de concordância nominal;

7) Traços de oralidade;

8) Fusão de construções da língua alvo.

Assim, percebe-se que os desvios localizados apresentam instâncias comuns no que se refere ao modo como comprometem a clareza textual, sendo as categorias (1), (2), (3) e (4) agrupamentos de problemas relacionados a itens lexicais e/ou gramaticais; (5) e (6), de problemas gerais relacionados à concordância; (7), de transferência de marcas do português falado percebidas via leitura labial ou texto escrito; e (8), de problemas envolvendo construções típicas do PB.

Com relação aos problemas envolvendo itens lexicais e/ou gramaticais, foi possível identificar quatro possibilidades de comprometimento textual. De uma maneira mais categórica, essas incidências compreenderam problemas provenientes da inserção indevida, repetição, troca e apagamento de itens de natureza lexical ou gramatical, encerrando quatro categorias. Dentro dessas categorias, destaca-se a proeminência de problemas, sobretudo relativos ao uso de preposições, como se vê na tabela abaixo: 


\begin{tabular}{|c|c|c|c|c|c|c|c|c|}
\hline \multicolumn{9}{|c|}{ Desvios envolvendo itens gramaticais e lexicais } \\
\hline $\begin{array}{c}\text { Natureza do } \\
\text { item }\end{array}$ & \multicolumn{2}{|c|}{ Repetição } & \multicolumn{2}{|c|}{$\begin{array}{c}\text { Inserção } \\
\text { Indevida }\end{array}$} & \multicolumn{2}{c|}{ Troca } & \multicolumn{2}{c|}{ Apagamento } \\
\cline { 2 - 8 } & $\begin{array}{c}\text { Forma } \\
\text { I }\end{array}$ & $\begin{array}{c}\text { Informa } \\
\text { I }\end{array}$ & $\begin{array}{c}\text { Forma } \\
\text { I }\end{array}$ & $\begin{array}{c}\text { Informa } \\
\text { I }\end{array}$ & $\begin{array}{c}\text { Forma } \\
\text { I }\end{array}$ & $\begin{array}{c}\text { Informa } \\
\text { I }\end{array}$ & $\begin{array}{c}\text { Forma } \\
\text { I }\end{array}$ & $\begin{array}{c}\text { Informa } \\
\text { I }\end{array}$ \\
\hline $\begin{array}{c}\text { Gramatical } \\
\text { sem tipo } \\
\text { predominant } \\
\text { e }\end{array}$ & 01 & 01 & - & - & - & - & - & - \\
\hline $\begin{array}{c}\text { Gramatical } \\
\text { do tipo } \\
\text { preposição }\end{array}$ & - & - & 04 & 02 & 03 & 01 & 05 & 09 \\
\hline $\begin{array}{c}\text { Gramatical } \\
\text { do tipo } \\
\text { pronome } \\
\text { relativo }\end{array}$ & - & - & - & - & - & - & - & 02 \\
\hline $\begin{array}{c}\text { Gramatical } \\
\text { do tipo } \\
\text { conjunção } \\
\text { integrante }\end{array}$ & - & - & - & - & - & - & - & 05 \\
\hline \begin{tabular}{c} 
Lexical \\
\hline
\end{tabular} & 01 & - & - & - & 07 & - & 01 & - \\
\hline
\end{tabular}

Tabela 3 - Desvios envolvendo itens gramaticais e lexicais

Exemplificamos de (a) a (d) algumas das ocorrências referentes aos resultados da Tabela 3:

(a) "Você sabe de me dizer se tem como fazer o pagamento do boleto da coleção da formatura por mensal sem juros?"

(b) "Porque estou pagando outra faculdade do meu sobrinho, mas estão tudo atrasado por conta meus problemas particulares"

(c)“Como resolver a solução para não ter problema? O motivo é a atualização de Java ou o mesmo problema do programa do curso?"

(d) "Você sabe de me dizer se tem como fazer o pagamento do boleto da coleção da formatura por mensal sem juros? (sic)".

Nota-se que em (a) o informante selecionou uma preposição, produzindo uma sequência distorcida do padrão [SABER + V. INFINITIVO], possivelmente, tomado pelo padrão [SABER + DE + NOME/PRONOME], o que resultou em uma escolha agramatical em português. Por outro lado, em (b), o que se vê é justamente o inverso: há apagamento da preposição, o que também aconteceu em dados com conjunções 
integrantes e verbos copulativos. No exemplo (c), apesar da troca, é possível recuperar a intenção do indivíduo em sanar sua dúvida acerca da resolução de um problema, mas, durante a seleção do item na memória, acabou por acessar a forma antônima.

No que se refere à repetição de itens, categoria (2), observamos que, das suas três ocorrências, duas envolveram itens gramaticais e uma lexical. O exemplo (d) traz uma sequência combinatória [da colação + da formatura] não esperada entre os itens lexicais. A repetição nos pareceu um reforço de informação, em que se identifica acionamento de estratégia para resolver a falta de clareza do significado de cada um dos itens em competição, o que seria perfeitamente compreensível na produção de um aprendiz de L2.

Além dos problemas com troca, apagamentos, inserções e repetições de itens lexicais/gramaticais, também foi observada grande incidência de desvios envolvendo concordância, tanto verbal, quanto nominal, além de alguns casos de troca de modo verbal em ambos os registros, como vemos abaixo:

(e) "(...) então temos avisar mais rápido possível e evitar o desperdício dos encontros. Cada mulher e homem trazem as bebidas e as carnes".

(f) "Caros colegas, não esquecem o compromisso pra os preparativos de festa pra comemorar os encontros de amigos e colegas da escola que faz tempão não se vê e nem encontra."

(g)“Caso queriam ver o meu currículo e currículo lattes, eu envio o meu para você por e-mail ou entrega na própria O Globo (...)"

Como se vê, há um desvio de concordância verbal padrão no dado (e), uma vez que o autor selecionou morfema de plural ao usar o verbo trazer, o que possivelmente pode ter sido motivado pela proximidade dos itens mais salientes- mulher e homem- , quando, pela norma padrão, a concordância indicada se faz com o item cada. $O$ mesmo problema também é observado no dado $(\mathrm{g})$, com os verbos querer e entregar. Verificamos seleção de morfema plural no primeiro verbo, quando o referente parece ser uma única pessoa (você) e de morfema de terceira pessoa no segundo verbo, quando o referente é eu. Em (f), o exemplo destacado apresenta troca de modo verbal, 
observável na forma selecionada, correspondente ao modo indicativo (esquecem) e não, ao imperativo (esqueçam), como demanda o contexto. É importante destacar que as duas formas são visualmente pouco distintas, o que não contribui para armazenamento detalhado de forma e significado (que inclui intenções distintas).

Em geral, problemas relacionados à concordância e escolhas agramaticais envolvendo itens lexicais/gramaticais são esperados durante a aprendizagem de uma L2, seja na modalidade escrita, na falada, ou mesmo na sinalizada, muitas vezes oriundas do processo de transferência da L1. Nesse processo, diferentes fenômenos podem ocorrer. Se há convergência entre construções entre a $L 1$ e a $L A$, o processo favorece a aquisição. Se, por outro lado, as construções divergem de uma língua para outra, agramaticalidades podem ocorrer pela transferência direta de construções da L1 na produção em L2, ou por choque com outras construções da L2, em que novas construções emergem com a configuração de mescla entre diferentes construções da LA, ou entre construções da L1 e da LA. Seja qual for o caso, o que em geral emerge são estruturas agramaticais na L2, com comprometimento estrutural/discursivo. Com base nisso, sabendo que o processo de aprendizagem de escrita de PBL2 por surdos é potencialmente capaz de apresentar marcas interlinguísticas, apresentamos resultados referentes às duas últimas categorias propostas, a saber, categoria (7), transferência da oralidade do $P B$, e categoria (8), mescla de construções da $L A$.

A categoria (7), que apresentou um total de 8 ocorrências, sendo 5 no registro informal e 3 no formal, reúne fenômenos observados nos textos de surdos que parecem ter sido motivados pela influência da oralidade da língua portuguesa. Em outras palavras, devido ao alto nível de oralização dos informantes desta pesquisa, acredita-se que certas particularidades agrupadas nessa categoria correspondam ao português falado. Os dados abaixo ilustram o que chamamos de transferência da oralidade do PB: (h) "espero isso o Fies me aprova o mais rápido possível e fiquei sabendo isso não é fácil, pois tem gente está concorrendo, mas torce por mim para dê tudo certo."

No exemplo (h), nota-se que o uso das conjunções e e mas, marcadores discursivos majoritariamente, recorrentes tanto na fala, quanto na escrita da língua portuguesa, integram, aqui, a organização do discurso escrito, de modo mais convergente com suas possibilidades na modalidade falada. Tais usos favorecem a 
hipótese de que o texto escrito de um indivíduo surdo oralizado pode apresentar transferências de uma modalidade (falada) à outra (escrita), assim como ocorre naturalmente com ouvintes em sua produção escrita e no curso de qualquer produção em L2.

A última categoria proposta por esta pesquisa revela problemas causados pela mescla de construções da língua alvo (LA), no caso, a língua portuguesa. Esse fenômeno consiste na fusão de duas construções de mesmo sentido na LA. Instâncias dessa categoria foram mais proeminentes no registro formal, em que ocorreram 4 desvios desse tipo, ao passo que, no informal, somente 1. Acredita-se que essa quantificação tenha apresentado essa oscilação justamente pelo nível de formalidade exigido na situação de produção dos textos, sendo o registro formal mais suscetível devido à tentativa de adequação à norma culta. A seguir, alguns exemplos:

(i) "(...), mas isso vai me ajudar muito para conseguir pagar outras contas atrasos."

(j) "Gostaria de saber se tem como possível de me enviar suas matérias na sala de aula para estudar em casa e se caso estiver algumas atividades para fazer, por favor, me encaminhe".

Percebe-se que, no exemplo (i), a utilização de contas atrasos, parece vir à tona, associando os padrões de duas construções possíveis em PB, [contas em atraso] e [contas atrasadas]. Uma evidência para tal ocorrência seria a concordância de plural em atrasos, posto que aparenta uma interpretação de que atraso está atuando como modificador nominal do item contas, fator que vai ao encontro da suposta existência da construção [contas atrasadas] mesclada à [contas em atraso]. O fenômeno da mescla de construções parece se repetir no exemplo (j), em se tem como possível de me enviar, o que presumivelmente é oriundo da mescla entre as construções [SE + TER COMO]e [SE + SER POSSÍVEL].

De maneira geral, o mapeamento das 8 categorias, no tocante ao grau de formalidade, mostrou-se de forma distinta nos dois registros, como evidenciam os gráficos abaixo: 


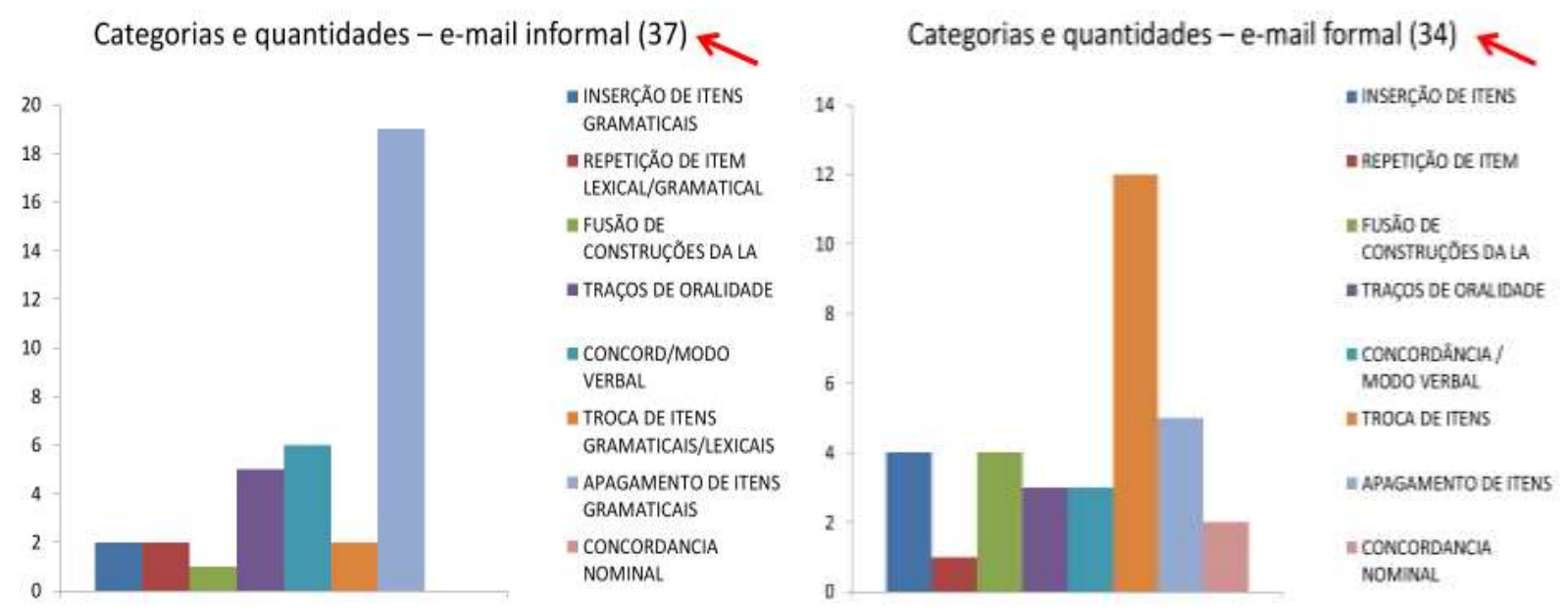

Gráfico 1 - Categorias e Quantidades - e-mail informal

Gráfico 2 - Categorias e Quantidades - e-mail formal

No registro informal, percebe-se que a categoria de maior saliência foi a de apagamentos de itens. Possivelmente, em razão da não ativação de meta-atenção para adequação das sequências de preenchimento não aleatório,exigido pelas construções selecionadas nos textos em PB, o discurso tornou-se mais livre e mais propenso às interferências da LIBRAS que possui grande tendência de não realização fonológica de certos itens gramaticais. Já no registro formal, ressalta-se a categoria troca de itens, denotando justamente o contrário, uma vez que, por questões de adequação à formalidade, parece ter havido maior suscetibilidade a hipercorreções. $A$ necessidade de adesão ao registro formal talvez tenha sido responsável por um maior uso, inadequado, de formas que seriam mais próximas de outras de ordem mais formal.

\section{Segunda etapa da pesquisa: situação das categorias mapeadas em diferentes níveis coesivos no plano discursivo}

Após a identificação das oito categorias de desvios encontrados nos e-mails formais e informais dos surdos envolvidos, buscou-se analisar em que nível elas comprometiam a coesão textual. Dessa maneira, nesse segundo momento, o olhar se voltou explicitamente à frequência com que as instâncias detentoras de desvios e/ou agramaticalidades em LP apareceriam nos níveis intraoracional, interoracional, 
interperíodo e interparágrafo. O resultado dessa etapa pode ser visto na configuração do gráfico abaixo:

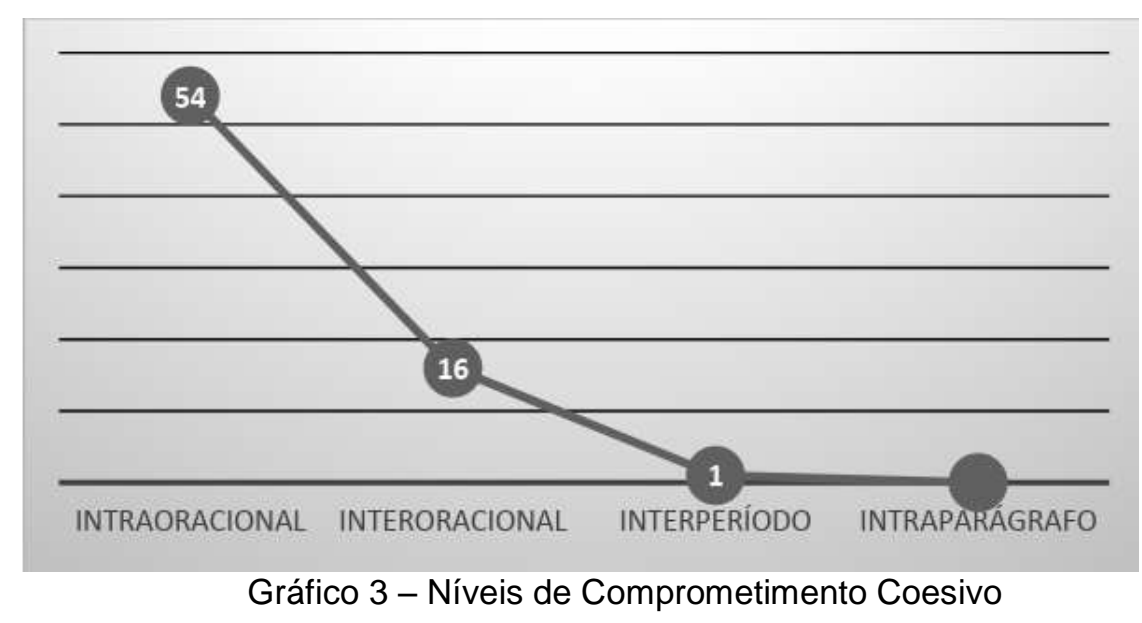

Notoriamente, a maioria dos problemas categorizados na primeira etapa da investigação foram vistos em nível intraoracional, isto é, atuando dentro de uma única oração. Foram mais comuns, nesse caso, categorias envolvendo problemas com itens gramaticais/lexicais e a categoria de concordância verbal/nominal.

$\mathrm{Na}$ escala, em segundo lugar, estavam os problemas que acometeram a inteligibilidade textual em nível interoracional. Em tais casos, os desvios apontados encontravam-se alojados entre duas sentenças, apresentando, portanto, uma implicação mais acentuada no que se refere à coesão textual, como mostram os trechos abaixo:

(k) "Encaminho-o em anexo com meu atestado médico $\underline{\mathbf{e}}$ vou ficar repouso em 15 dias a partir da data de hoje por motivo da cirurgia para não perder minhas faltas da sua sala de aula"

(I) "Se vai, me encontra no metrô São Cristóvão,15h. Pode levar seus filhos. Leva lanche, bebida, também leva repelente evita mosquito picar."

Embora sejam poucas as ocorrências, contabilizamos, também, problemas operantes entre dois períodos distintos, correspondentes ao nível interperíodo. Se por um lado apresentaram frequência reduzida, por outro, representaram ocorrências potencialmente capazes de propagar maiores danos à textualidade. Um exemplo 
desse tipo de desvio pode ser observado no dado a seguir, cuja categoria presente é a de troca de itens gramaticais/lexicais, em que só se consegue recuperar sentido, caso o item portanto seja substituído por no entanto.

(m) "Caros colegas, não esquecem o compromisso pra os preparativos de festa pra comemorar os encontros de amigos e colegas da escola que faz tempão não se vê e nem encontra. Portando, percebemos que alguns não têm condição ou tem condição para ir comparecer. (sic)"

No material utilizado para a composição desta pesquisa, porém, não houve nenhuma ocorrência compatível com a relação interparágrafo.

Sendo assim, essa etapa, contribuiu para uma visão mais abrangente a respeito do modo como os desvios categorizados podem ser previsíveis e inibidores da coesão do texto escrito em PBL2. Por tabela, oferece subsídios para reflexões a futuros projetos de elaboração de materiais didáticos, capazes de atuar diretamente nos pontos aqui descritos, em contexto de provável emergência.

\section{Terceira etapa da pesquisa: proposição de processos cognitivos subjacentes às categorias encontradas e ao desenvolvimento da Interlíngua (IL)}

Adotando a concepção de que fenômenos linguísticos não ocorrem ao acaso e isolados de seus respectivos contextos de uso, investigamos os processos cognitivos que se poriam subjacentes às ocorrências dos desvios mapeados nos textos investigados. Nesse caso, com apoio dos pressupostos teóricos basilares a este trabalho, a perspectiva da terceira e última etapa da presente investigação integra uma relação de interface entre a superfície textual, isto é, os usos reais apresentados nos dados expostos, e possíveis estruturas cognitivas que subjazem os diferentes níveis de produção da escrita em L2.

Foi possível deduzir a atuação de quatro tipos distintos de processos cognitivos subjacentes às ocorrências: (1) hipercorreção/supergeneralização; (2) interferência da L1; (3) interferência da oralidade da LA; (4) mescla de construções da LA. 
Entende-se por hipercorreção a interpretação tendenciosa e parcial de determinada regra gramatical de uma língua, a qual é aplicada inadequadamente em um contexto alheio ao esperado, podendo, ou não, indicar casos de supergeneralizações. Em outras palavras, o indivíduo teria conhecimento da regra aplicável no sistema linguístico da língua alvo, mas, no momento de sua aplicação na comunicação escrita e/ou falada, a colocaria em prática por meio de um desvio não aceito em sua própria pauta. Dentre os dados indicados como exemplares de produtos desse processo cognitivo, destacam-se:

(n) "Encaminho-o em anexo com meu atestado médico e vou ficar repouso em 15 dias a partir da data de hoje por motivo da cirurgia para não perder minhas faltas da sua sala de aula"

(o) "Cada mulher e homem trazem as bebidas e as carnes. Vou organizar a lista tem que ser informada para cada um escolher e levar sem preocupação. Há, não esquecem também levar cervejas sem duvida. Risos"

Por outro lado, se no processo de hipercorreção/supergeneralização há uma motivação proveniente dos aspectos linguísticos da língua alvo, no processo de interferência da L1, como o próprio nome sugere, a motivação é dada por transferências de aspectos morfossintáticos do sistema linguístico da primeira língua para modalidade escrita da segunda. Naturalmente, o falante recorre à língua materna, a fim de obter suporte que lhe possibilite uma produção em L2 sem tantas lacunas, fator que, por vezes, se mostra favorável ao alcance do padrão esperado. Entretanto, ao se tratar de línguas distintas, com gramáticas distintas, como, por exemplo, português e LIBRAS, as transferências da L1 podem implicar desvios de baixa, média ou alta complexidade. Tomamos como transferência da L1 o apagamento de item gramatical, integrante de uma sequência recorrente em PB, observável, por exemplo, na construção [vou ficar repouso], retirada de (n).

Ainda, indicamos o processo de interferência da oralidade na modalide escrita, proposto em razão de ocorrências nos dados agrupados na categoria (7). Este fenômeno parece estar atrelado ao grau de oralização dos surdos participantes da pesquisa, além de indicar reflexão mais abrangente sobre interferência, já que pode 
ocorrer entre L1 e L2 ou entre modalidades distintas (falada, escrita, sinalizada). Ocorrências como(p), a seguir, seriam motivadas pelo processo de interferência da oralidade:

(p) "(...) vou organizar a lista tem que ser informada para cada um escolher e levar sem preocupação. Há, não esquecem também levar cervejas sem duvida".

Independentemente do equívoco ortográfico, em que se observa a inversão na sequência das letras $A$ e $H$, o que o surgimento da forma com valor expressivo sugere é a transferência direta da oralidade na modalidade escrita, ainda que tal forma possa ser encontrada em material escrito em diferentes gêneros discursivos.

O último processo cognitivo apontado seria o que promove a categoria (8), estando mais relacionado aos aspectos estruturais e discursivos da gramática da $L A$. Esse processo versa sobre o uso e mescla de construções típicas do PB, denotando o modo como o falante projeta mentalmente, ao mesmo tempo, determinadas expressões portadoras de valores semânticos bem delineados e cabíveis a um dado contexto. São exemplos de ocorrências motivadas por tal processo cognitivo as sentenças (i) e (j) da seção de mapeamento de categorias. Em termos quantitativos, os gráficos abaixo mostram a atuação desses processos cognitivos subjacentes ao desenvolvimento da Interlíngua nos e-mails analisados, respectivamente, no registro informal e formal.

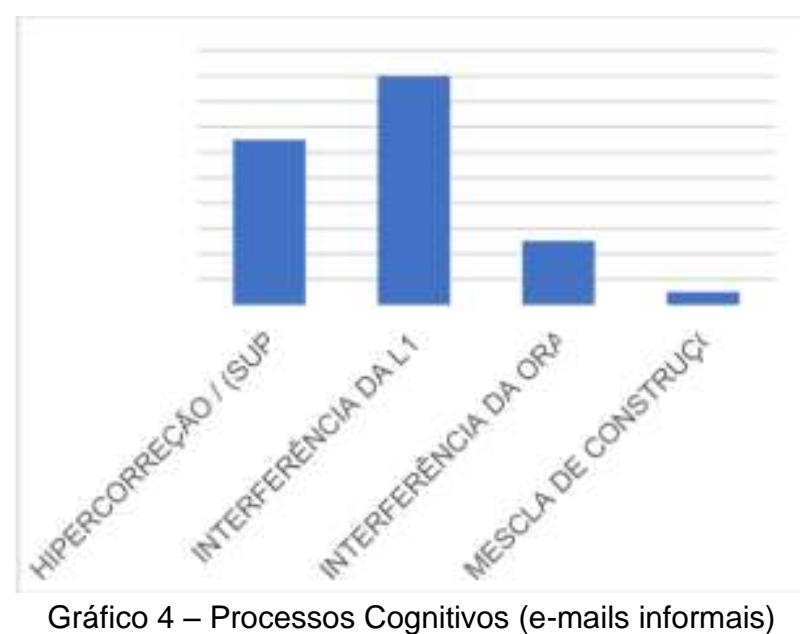

Gráfico 4 - Processos Cognitivos (e-mails informais)

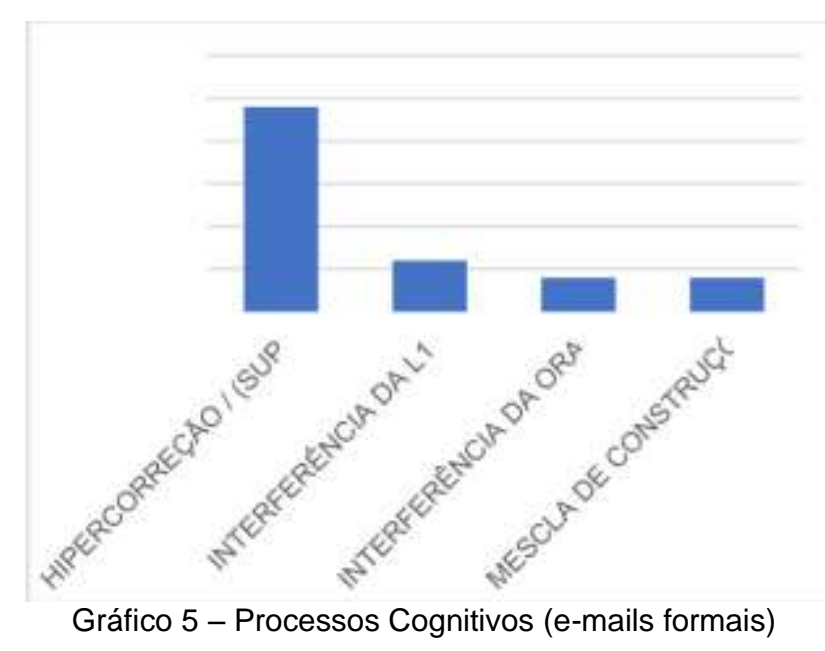

Gráfico 5 - Processos Cognitivos (e-mails formais) 
Ressaltamos o modo como esses processos cognitivos se redistribuem de maneiras distintas, a depender do registro em questão. Assim, é coerente apontar que, nos e-mails informais, o processo de maior saliência é o de interferência da L1 em decorrência, acreditamos, de maior liberdade concedida pelo contexto de interlocução. Por outro lado, nos formais, nota-se a hipercorreção/supergeneralização, como processos mais recorrentes, possivelmente, em razão do acionamento de consciência discursiva que impõe atenção às exigências do contexto de interação.

\section{Considerações finais}

A investigação aqui apresentada não esgota, nem superficialmente, a grande necessidade de descrição e análise acerca dos problemas emergentes no texto escrito do surdo, no entanto, sua principal contribuição consiste na proposta de um modelo investigativo diferenciado: a descrição dos problemas de agramaticalidade e desvios de norma culta, permeada pelo impacto desses problemas no nível da textualidade e em busca dos possíveis processos subjacentes ao surgimento dos fenômenos. Sem dúvida, essa é uma tentativa de mapeamento mais aprofundado e eficaz desse objeto de estudo e, acreditamos que, a médio prazo, possa contribuir sobremaneira para iniciativas aplicáveis, de cunho educacional, para o ensino dessa parcela tão singular da população brasileira: nossos alunos surdos.

\section{Referências Bibliográficas}

BYBEE, J. Usage-based grammar and second language acquisition. In: P. Robinson and N. Ellis (eds.), Handbook of Cognitive Linguistics and Second Language Acquisition. New York: Routledge. 216-236. 2008.

Press, 2010.

. Language, usage and cognition. Cambridge: Cambridge University

BROWN, D. Principles of language learning and teaching. New Jersey: Prentice Hall, 1994.

CUNHA, M. A. Language, usage and cognition. DELTA, vol.29, n.1. São Paulo, 2013. Disponível em: 
<http://www.scielo.br/scielo.php?script=sci_arttext\&pid=S0102-4450201300010000. Acesso em 18/04/2017>.

ELLIS, N.; LARSEN-FREEMAN, D. Language emergence: implications for applied linguistics - introduction to the special issue. Applied Linguistics, v. 27, n. 4, p. 55889, 2006.

FREITAS. R. Reflexos pragmático-discursivos da L1 na aquisição de inglês como L2: um estudo sobre o uso da cláusula VS. Dissertação de Mestrado. UFRJ: Rio de Janeiro. 2006.

A constituição discursivo-gramatical da construção (X)VS em inglês como L2: indícios de formação da interlíngua. Tese de Doutorado. UFRJ: Rio de Janeiro. 2011.

HOPPER, P. Emergent Grammar. Berkeley Linguistic Society, n. 13, p 139-57, 1987

LARSEN-FREEMAN, D. Chaos/complexity science and second language acquisition. Applied Linguistics, n. 18, p. 141-65, 1997.

LONG, M. The least a second language theory needs to explain. In: S. Gass \& L. Selinker (eds), Language transfer in language learning, 217-32. Rowley, Mass.: Newbury House. 1993.

MARCUSCHI, L. Gêneros textuais: definição e funcionalidade. In: DIONÍSIO, A. P.; MACHADO, A. R.; BEZERRA, M. A. (Org.). Gêneros textuais e ensino. 4. ed. Rio de Janeiro: Lucerna, 2005.

ODLIN, T. Cross-linguistics influence in language learning. Cambridge: Cambridge University Press. 1989.

SELINKER, L. \& LAMENDELLA, J. The role of extrinsic feedback in interlanguage fossilization: A discussion of "Rule fossilization: A tentative model." Language Learning 29: 363-375. 1979.

\footnotetext{
Sobre os autores

Roberto de Freitas Junior

Graduado em Português/Inglês pela Universidade Federal do Rio de Janeiro (1999), possui Especialização em Língua Inglesa pela PUC-RIO (2001), Mestrado em Linguística pela Universidade Federal do Rio de Janeiro (2006) e Doutorado em Linguística pela Universidade Federal do Rio de Janeiro (2011). Diretor Adjunto de Cultura e Extensão da FL/UFRJ e professor adjunto de Estudos Linguísticos do dpto de Letras-LIBRAS/UFRJ. Atua nas áreas de linguística funcional, linguística cognitiva, modelos baseados no uso, principalmente com aquisição de L2, ordenação vocabular, transitividade e estrutura argumental e informacional.
} 


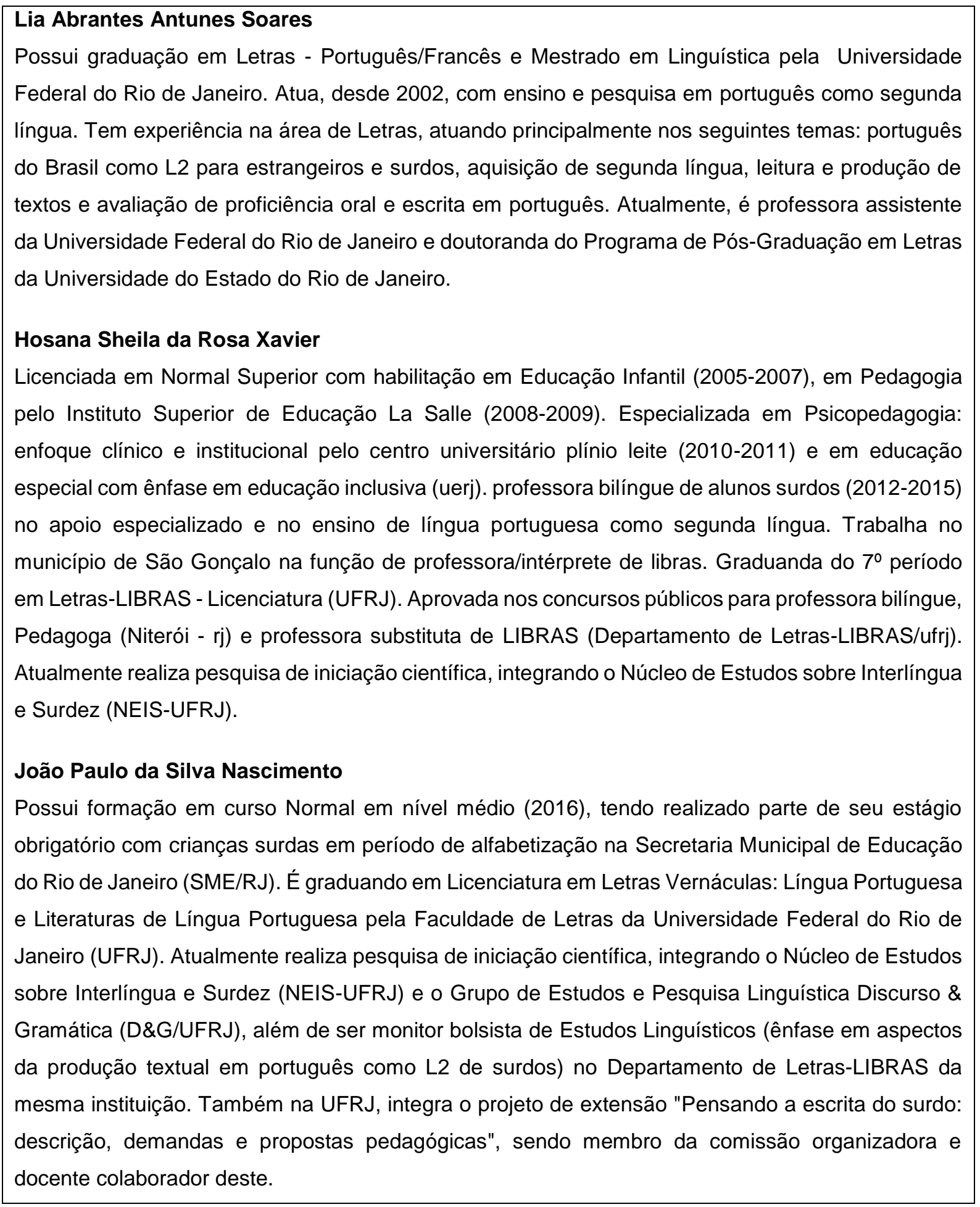

